\title{
Porous starch and its application in drug delivery systems
}

\author{
Monika Sujkka ${ }^{1, A, D}$, Urszula Pankiewicz ${ }^{1, C, F}$, Radosław Kowalski ${ }^{1, E}$, Karolina Nowosad ${ }^{1, B}$, Agnieszka Noszczyk-Nowak2,E,F \\ ${ }^{1}$ Department of Analysis and Evaluation of Food Quality, University of Life Sciences in Lublin, Poland \\ ${ }^{2}$ Department of Internal Medicine and Clinic of Diseases of Horses, Dogs and Cats, Wrocław University of Environmental and Life Sciences, Poland \\ A - research concept and design; B - collection and/or assembly of data; $C$ - data analysis and interpretation; \\ $\mathrm{D}$ - writing the article; $\mathrm{E}$ - critical revision of the article; $\mathrm{F}$ - final approval of the article
}

Address for correspondence

Monika Sujka

E-mail:monika.sujka@up.lublin.pl

\section{Funding sources}

None declared

Conflict of interest

None declared

Received on August 10, 2018

Reviewed on 0ctober 17, 2018

Accepted on November 15, 2018

Cite as

Sujka M, Pankiewicz U, Kowalski R, Nowosad K,

Noszzzyk-Nowak A. Porous starch and its application

in drug delivery systems. Polim Med. 2018;48(1):25-29.

doi:10.17219/pim/99799

DOI

10.17219/pim/99799

Copyright

○ 2018 by Wroclaw Medical University

This is an article distributed under the terms of the

Creative Commons Attribution Non-Commercial License

(http://creativecommons.org/licenses/by-nc-nd/4.0/)

\begin{abstract}
In recent years, starch has become a new potential biomaterial for pharmaceutical applications. This biopolymer has unique physicochemical and functional characteristics, as well as various advantages such as low price, relative ease of isolation in pure form from the plant source, non-toxicity, biodegradability, good biocompatibility, and interaction with living cells. Starch is currently used in pharmacy as a binder, disintegrating agent, film-forming material, raw material for production of microspheres and nanoparticles, and a component of drug delivery systems. Porous starch, which can be obtained with physical, chemical and enzymatic methods of modification, has a large specific surface area thanks to the presence of pores and channels. It has excellent adsorption capacity and can be used to enhance the dissolution rate of poorly soluble drugs or as shell material to improve the stability and water-solubility of compounds. As a component of drug delivery systems, porous starch has another advantage: it is biodegradable, so there is no need to remove it from the body after the release of the active agent.
\end{abstract}

Key words: starch, porosity, drug delivery systems 


\section{Starch and its properties}

Starch is a natural storage polysaccharide in higher plants and the most common carbohydrate in human and animal diets. It is found in leaves, stems, seeds, fruits, roots, and tubers. The main sources of starch for industrial applications are maize $(82 \%)$, wheat $(8 \%)$, potatoes $(5 \%)$, and cassava (5\%). ${ }^{1}$ Structurally, starch is composed of linear amylose and highly branched amylopectin, both made up of D-glucose units joined together via glycosidic linkages: $\alpha(1 \rightarrow 4)$ and $\alpha(1 \rightarrow 6)$ (only in branch points). It is laid down in the form of semi-crystalline granules of different sizes (from $1 \mu \mathrm{m}$ to over $100 \mu \mathrm{m}$ in diameter) and shapes. ${ }^{2}$ The shape of a granule can vary from oval/round to polyhedral, and can be characteristic of a genus and species.

One of the most characteristic properties of starch is its ability to gelatinize and form thick pastes. This process takes place when starch is heated in excess water and results in irreversible disruption of the molecular order within a granule. Gelatinization is associated with diffusion of water into granules and their radial swelling, loss of starch crystallinity and amylose leaching into the solution. Granule swelling and disruption produce a viscous paste consisting of a continuous phase of solubilized amylose and/or amylopectin, and a discontinuous phase of granule fragments. On cooling, amylose and linear segments of amylopectin reassociate and form an ordered gel network. The formation of the junction zones of a gel can be considered to be the first stage of starch molecule crystallization. As starch pastes are cooled and stored, the starch becomes progressively less soluble. This process is called retrogradation. ${ }^{3}$ In the food industry, starch retrogradation is a highly undesirable phenomenon, especially when a product requires freeze-thaw stability, but on the other hand retrograded starch is classified as one of the types of resistant starch considered a dietary fiber. ${ }^{4}$

Starch - in particular the linear component amylose is able to form inclusion complexes with small molecules (e.g., lipids, alcohols, lactones, or iodine) and act as an encapsulating agent. The amylose wraps itself around the guest molecule and forms a single left-handed helix structure (so-called $\mathrm{V}$ amylose). ${ }^{5}$ The number of glucose units in each turn of the helical coil $(6,7$ or 8$)$ is dependent on the size of the guest molecule, and the host molecule is able to expand or contract around the guest. These inclusion complexes can be used in the food and pharmaceutical industries for the controlled and targeted delivery of nutraceuticals and/or drugs to the lower gastrointestinal tract. ${ }^{5,6}$

\section{Porous starch}

The definition of porosity states that it is the ratio of pore volume to the volume of the solid phase. Solid materials can contain closed pores, as well as a network of both one- or two-side opened pores, combined with each other or not. The classification of pores based on the size of their diameter is as follows: macropores (diameter $>50 \mathrm{~nm}$ ), mesopores (diameter between $2 \mathrm{~nm}$ and $50 \mathrm{~nm}$ ) and micropores (diameter $<2 \mathrm{~nm}$ ). ${ }^{7}$ The occurrence of pores on the granule surface of sorghum, maize, millet, wheat, rye, and barley (along the equatorial groove of large granules) has been confirmed by microscopic observations. Granules of tapioca, rice, oat, canna, and arrowroot appear to be smooth, but there is no consensus among researchers about the presence of pores on the surface of potato starch granules. ${ }^{8,9}$ Fannon et al. revealed that, apart from surface pores, there are also specific channels and cavities in maize starch granules. ${ }^{10}$ The researchers suggested that surface pores are openings to serpentine channels penetrating the granule interior. ${ }^{10}$ According to Huber and BeMiller, most channels penetrate granules from the external surface towards a cavity at the hilum, but the depth of penetration can vary. ${ }^{11}$ Channels appeared to be open, whereas cavities tended to be closed. Huber and BeMiller reported the presence of such cavities in maize, waxy maize and sorghum starch granules. ${ }^{11}$ It has been proven that the porosity of starch granules significantly influences its chemical reactivity. The presence of pores, channels and cavities increases the size of the surface area that can potentially be available for chemical or enzymatic reactions. ${ }^{11}$ Pore size is an important factor in determining the loading capacity of starch granules for water and oil. ${ }^{12}$ Porous starch can also be a good carrier for bacteria, enzymes, flavors, or bioactive compounds such as drugs. ${ }^{13,14}$

The applicability of starch in a native form is limited because of its sensitivity to processing conditions such as extreme temperature, low $\mathrm{pH}$, high shear rate, and freezethaw variation. In the pharmaceutical industry, native starch has traditionally been used for the production of granules, capsules and tablets. Builders and Arhewoh recently published an excellent review of pharmaceutical applications of unmodified starch. ${ }^{15}$ For many purposes, however, a modification of starch by chemical, physical or enzymatic methods, or combinations of these methods, is required. Among them, chemical methods are the most commonly used. The 3 available hydroxyl groups at position $\mathrm{C} 2, \mathrm{C} 3$ and $\mathrm{C} 6$ can be modified through esterification, etherification and oxidation. ${ }^{16}$ The starch preparations obtained as a result of modification have different properties depending on the reagent used and the reaction. ${ }^{17}$ As a result of starch modification, the following properties may be changed: granularity, water binding capacity and solubility, paste viscosity, gelatinization temperature, the rheological stability of pastes, paste transparency, retrogradation, adhesion, emulsifiability, texturizing properties, thickening, film formation, and/or chemical reactivity. ${ }^{18}$

Porous starch, which has received significant attention in recent years, can be obtained by physical, chemical or enzymatic methods, but ultrasonic and enzyme treatments have 
been most frequently reported. ${ }^{19-23}$ Other proposed methods are the solvent exchange technique, ${ }^{24}$ extrusion, ${ }^{25,26} \mathrm{mi}$ crowave foaming, ${ }^{27}$ grinding, ${ }^{28}$ or enzymatic hydrolysis followed by oven-, spray- or vacuum freeze-drying. ${ }^{29}$ Table 1 presents an overview of the methods applied for obtaining porous starch, as well as the specific surface area and average pore size of the products. Porous starch can be used for dissolution enhancement of poorly soluble drugs, has excellent adsorption capability because of its large specific surface area, or can be used as shell material to improve the stability and water-solubility of compounds. ${ }^{30}$

\section{Porous starch in drug delivery systems}

Drug delivery systems usually include particulate carriers (composed primarily of lipids and/or polymers) and associated therapeutics. They are designed to alter the pharmacokinetics and biodistribution of the associated drugs, or to function as drug reservoirs, or both. ${ }^{31}$ The ideal drug delivery system should be comfortable for the patient, inert, biocompatible, bioadhesive, and capable of high drug loading. Porous starch meets all these conditions. Starch is officially accepted by all major regulatory agencies for use in various oral drug delivery systems. ${ }^{32}$ Starch polymer chains are hydrolyzed into smaller biologically acceptable compounds, so there is no need to remove the drug delivery system from the body after the release of the active agent.

The formation of inclusion complexes, micro- or nanoparticles, is one method of improving the oral delivery of poorly water-soluble drugs and drug stability. It has been found that biodegradable porous starch foam (BPSF) with a nanoporous structure, low density, and high specific surface area and pore volume has better characteristics than an inorganic carrier. ${ }^{33}$ In in vitro and in vivo drug release studies, Wu et al. showed that the use of BPSF enhanced the release and oral bioavailabil- ity of lovastatin in comparison with crude lovastatin and commercial capsules. ${ }^{34}$ The drug absorbed by the BPSF was partially present as microcrystals, partially in amorphous form distributed in the pores of the BPSF and partially in crystalline form distributed on the surface of the BPSF. ${ }^{30}$ Starch macrocellular foam (SMF) has been used to improve the dissolution rate and oral bioavailability of nitrendipine (NDP); the results demonstrated that SMF can be a promising carrier for the oral delivery of poorly water-soluble drugs. ${ }^{35}$ The use of porous starch as a carrier for carbamazepine also enhanced its solubility. ${ }^{13}$ García-González et al. reported that starch aerogel microspheres can be used as carriers for ketoprofen, as they showed high loading capacities. ${ }^{36}$ The researchers produced aerogel microspheres from starch and loaded them with poorly water-soluble drugs, ketoprofen and benzoic acid via supercritical $\mathrm{CO}_{2}$-assisted adsorption. The starch aerogel microspheres presented a higher specific loading capacity for ketoprofen than for benzoic acid, but they released the latter drug faster than the former one. ${ }^{31}$ Starch-based microparticles have been used for the entrapment and release of 3 corticosteroids: dexamethasone (DEX), 16 $\alpha$-methylprednisolone (MP) and $16 \alpha$-methylprednisolone acetate (MPA). ${ }^{37}$ The loading efficiencies of DEX and MPA were $82 \%$ and $84 \%$, respectively, followed by MP (51\%). The study showed that these starch-based systems were capable of sustained release of the entrapped steroids for up to 30 days. ${ }^{37}$

Jadhav and Vavia obtained supercritical processed starch nanosponge (SSNS) and used it as a carrier for poorly water-soluble fenofibrate. They reported significan dissolution enhancement of the SSNS formulation as compared to the plain drug, while an in vivo pharmacodynamic study showed that the SNSS-based formulation significantly improved the bioavailability of the drug. ${ }^{38}$ In a study by Pawar et al., porous starch was used to improve the dissolution and oral bioavailability of itraconazole; the results showed a significant increase in the release and oral bioavailability of the drug compared to the marketed product. ${ }^{39}$

Table 1. Overview of the methods used to obtain porous starch, its specific surface area and mean pore size

\begin{tabular}{|c|c|c|c|c|}
\hline Starch source & Method of modification & $\begin{array}{c}\text { Specific surface area } \\
{\left[\mathrm{m}^{2} / \mathrm{g}\right]}\end{array}$ & $\begin{array}{c}\text { Mean pore size } \\
{[\mathrm{nm}]}\end{array}$ & Reference \\
\hline NDA & solvent exchange method & 109.73 & $\sim 200$ & 13 \\
\hline Corn & hydrolysis with glucoamylase at $50^{\circ} \mathrm{C}$ for $1-8 \mathrm{~h}$ & $0.76-1.86$ & $200-1,150$ & 19 \\
\hline Rice, corn, wheat, potato & ultrasounds (20 kHz, 170 W, 30 min, in water or ethanol) & $0.16-1.27$ & $6.38-10.16$ & 22 \\
\hline NDA & solvent exchange method & 127.75 & $20-80$ & 34 \\
\hline Corn & emulsion-gelation method followed by supercritical drying & 127 & NDA & 44 \\
\hline Potato, corn & hydrolysis with a-amylase at $50^{\circ} \mathrm{C}$ for $60 \mathrm{~min}$ & $0.40-1.09$ & $11.63-23.85$ & 45 \\
\hline Wheat, rice & hydrolysis with a-amylase at $50^{\circ} \mathrm{C}$ for $60 \mathrm{~min}$ & $0.83-1.66$ & $8.06-17.87$ & 46 \\
\hline NDA & cross-linking followed by drying and milling & $39.80-49.80$ & NDA & 47 \\
\hline Waxy rice & enzymatic hydrolysis (a-amylase, amyloglucosidase and their mixture) & $1.15-2.34$ & $1.29-7.23$ & 48 \\
\hline Maize & sol-gel method and effective supercritical drying technique & 185.75 & $20-150$ & 38 \\
\hline
\end{tabular}

*NDA - no data available. 
Balmayor et al. applied an emulsion solvent extraction/ evaporation technique to develop starch poly- $\varepsilon$-caprolactone (SPCL) microparticles (size between $5 \mu \mathrm{m}$ and $900 \mu \mathrm{m}$ ) for use in drug delivery and tissue engineering (TE) applications. The experiments with dexamethasone (DEX) as the model drug showed that up to $93 \%$ of DEX was entrapped in SPCL microparticles, depending on the polymer concentration and the drug-to-polymer ratio. The authors suggested that the DEX release was initially governed mainly by diffusion, and then by degradation of the polymeric matrix. ${ }^{40}$ Ali et al. demonstrated that the use of porous starch as a carrier for carbamazepine (CBZ) enhanced the solubility of the drug, showing an improved in vivo performance compared to neat CBZ. ${ }^{13}$

Porous starch as a wall material can enhance the adsorbabilityand adhesive properties of microcapsules. Wang etal. used a spray-drying method of encapsulating lutein by using gelatin mixed with porous starch as wall materials. They obtained a high yield of product $(92.6 \pm 1.7 \%)$ and good encapsulation efficiency $(94.4 \pm 0.4 \%)$. The solubility and stability of the microcapsules were much higher than in the case of free lutein. ${ }^{41}$ Malafaya et al. produced starch-based porous material by the microwave baking method and used it as a carrier for a non-steroid antiinflammatory agent. ${ }^{42}$ A porous starch-based self-assembled nanodelivery system was developed by Zhang et al. to improve the oral absorption of insoluble probucol. The study showed that the oral bioavailability of the drug from the nanocarrier was improved about 10-fold compared to that of a free drug suspension. ${ }^{43}$

All the published results of experiments indicate that porous starch is a very promising material for pharmacological applications. However, more attention should be focused on investigating the relationship between pore size and the properties of a carrier (e.g., loading capacity and drug release behavior). Other significant problems are how to scale up the production and application of porous starch, and how to obtain a carrier with strictly defined parameters. It should also be noted that although starch is generally regarded as safe, its derivatives, especially in form of nano- and microparticles, may pose some safety challenges as components of drug delivery systems.

\section{References}

1. Le Corre D, Bras J, Dufresne A. Starch nanoparticles: A review. Biomacromolecules. 2010;11(5):1139-1153.

2. Tester RF, Karkalas J, Qi X. Starch-composition, fine structure and architecture. J Cereal Sci. 2004;39(2):151-165.

3. Copeland L, Blazek J, Salman H, Chiming Tang M. Form and functionality of starch. Food Hydrocoll. 2009;23(6):1527-1534.

4. Fuentes-Zaragoza E, Riquelme-Navarrete MJ, Sánchez-Zapata E, Pérez-Álvarez JA. Resistant starch as functional ingredient: A review. Food Res Int. 2010;43(4):931-942.

5. Putseys JA, Lamberts L, Delcour JA. Amylose-inclusion complexes: Formation, identity and physico-chemical properties. J Cereal Sci. 2010;51:238-247

6. Cohen R, Orlova $Y$, Kovalev M, Ungar $Y$, Shimoni E. Structural and functional properties of amylose complexes with genistein. J Agricultural Food Chem. 2008;56(11):4212-4218.
7. Sing KS. Reporting physisorption data for gas/solid systems with special reference to the determination of surface area and porosity. Pure Appl Chem. 1985;57(4):603-619.

8. Fannon JE, Hauber RJ, BeMiller JN. Surface pores of starch granules. Cereal Chem. 1992;69(3):284-288.

9. Sujka M, Jamroz J. Characteristics of pores in native and hydrolyzed starch granules. Starch/Stärke. 2010;62(5):229-235.

10. Fannon JE, Shull JM, BeMiller JN. Interior channels of starch granules. Cereal Chem. 1993;70(5):611-613.

11. Huber KC, BeMiller JN. Channels of maize and sorghum starch granules. Carbohydr Polym. 2000;41(3):269-276.

12. Jung $\mathrm{Y}$, Lee $\mathrm{B}-\mathrm{H}$, Yoo S-H. Physical structure and absorption properties of tailor-made porous starch granules produced by selected amylolytic enzymes. PLoS ONE. 2017;12(7):e0181372.

13. Ali MT, Fule R, Sav A, Amin P. Porous starch: A novel carrier for solubility enhancement of carbamazepine. AAPS PharmSciTech. 2013;14(3):919-926.

14. Zhu F. Encapsulation and delivery of food ingredients using starch based systems. Food Chem. 2017;229:542-552.

15. Builders PF, Arhewoh MI. Pharmaceutical applications of native starch in conventional drug delivery. Starch/Stärke 2016;68(9-10):864-873.

16. Khan F, Ahmad SR. Polysaccharides and their derivatives for versatile tissue engineering application. Macromol Biosci. 2013;13(4):395-421.

17. Tomasik P, Zaranyika MF. Nonconventional methods of modification of starch. Adv Carbohydr Chem Biochem. 1995;51:243-318.

18. Singh J, Kaur L, McCarthy OJ. Factors influencing the physico-chemical, morphological, thermal and rheological properties of some chemically modified starches for food applications: A review. Food Hydrocoll. 2007;21(1):1-22.

19. Chen $G$, Zhang B. Hydrolysis of granular corn starch with controlled pore size. J Cereal Sci. 2012;56(2):316-320.

20. Majzoobi M, Hedayati S, Farahnaky A. Functional properties of microporous wheat starch produced by a-amylase and sonication. Food Biosci. 2015;11(1):79-84.

21. Benavent-Gil Y, Rosell CM. Comparison of porous starches obtained from different enzyme types and levels. Carbohydr Polym. 2017;157:533-540.

22. Sujka M. Ultrasonic modification of starch: Impact on granules porosity. Ultrason Sonochem. 2017;37:424-429.

23. Zhang B, Cui D, Liu M, Gong H, Huang Y, Han F. Corn porous starch: Preparation, characterization and adsorption property. Int J Biol Macromol. 2012;50(1):250-256.

24. Chang PR, Yu J, Ma X. Preparation of porous starch and its use as a structure-directing agent for production of porous zinc oxide. Carbohydr Polym. 2011;83(2):1016-1019.

25. Guan JJ, Hanna MA. Extruding foams from corn starch acetate and native corn starch. Biomacromolecules. 2004;5(6):2329-2339.

26. Wlodarczyk-Stasiak M, Mazurek A, Pankiewicz U, Sujka M, Jamroz J. Porosity of starch-proteins extrudates determined from nitrogen adsorption data. Food Hydrocoll. 2014;36:308-315.

27. Sjöqvist M, Gatenholm P. Effect of water content in potato amylopectin starch on microwave foaming process. J Polym Environ. 2007;15:43-50.

28. Nagata K, Okamoto H, Danjo K. Naproxen particle design using porous starch. Drug Dev Ind Pharm. 2001;27(4):287-296.

29. Gao F, Li D, Bi C-H, Mao Z-H, Adhikari B. Application of various drying methods to produce enzymatically hydrolyzed porous starch granules. Drying Technology. 2013;31(13-14):1627-1634.

30. Zhou M, Shen L, Hong Y, Feng Y. Design and pharmaceutical applications of porous particles. RSC Adv. 2017;7:39490-39501.

31. Allen TM, Cullis PR. Drug delivery systems: Entering the mainstream. Science. 2004;303(5665):1818-1822.

32. Rowe RC, Shesky PJ, Quinn ME. Handbook of Pharmaceutical Excipients. $6^{\text {th }}$ ed. London, UK: Pharmaceutical Press; 2009:685-690.

33. Marques AP, Reis RI, Hunt JA. The biocompability of novel starchbased polymers and composites: In vitro studies. Biomaterials. 2002;23:1471-1478.

34. Wu C, Wang Z, Zhi Z, Jiang T, Zhang J, Wang S. Development of biodegradable porous starch foam for improving oral delivery of poorly water soluble drugs. Int J Pharm. 2011;403(1-2):162-169.

35. Zhao Y, Wu C, Zhao Z, et al. Preparation of starch macrocellular foam for increasing the dissolution rate of poorly water-soluble drugs. Pharm Dev Technol. 2015;21(6):749-754. 
36. García-González CA, Uy JJ, Alnaief M, Smirnova I. Preparation of tailor-made starch-based aerogel microspheres by the emulsiongelation method. Carbohydr Polym. 2012;88(4):1378-1386.

37. Silva GA, Costa FJ, Neves NM, Coutinho OP, Dias ACP, Reis RL. Entrapment ability and release profile of corticosteroids from starchbased microparticles. J Biomed Mater Res A. 2005;73A(2):234-243.

38. Jadhav NV, Vavia PR. Supercritical processed starch nanosponge as a carrier for enhancement of dissolution and pharmacological efficacy of fenofibrate. Int J Biol Macromol. 2017;99:713-720.

39. Pawar J, Ali MT, Fule R, et al. Biodegradable porous starch spheres as a novel carrier for enhancement of dissolution rate and oral bioavailability of itraconazole. Curr Drug Deliv. 2017;14(7):944-954.

40. Balmayor ER, Tuzlakoglu K, Azevedo HS, Reis RL. Preparation and characterization of starch-poly- $\varepsilon$-caprolactone microparticles incorporating bioactive agents for drug delivery and tissue engineering applications. Acta Biomater. 2009;5(4):1035-1045.

41. Wang Y, Ye H, Zhou C, Lv F, Bie X, Lu Z. Study on the spray-drying encapsulation of lutein in the porous starch and gelatin mixture. Eur Food Res Technol. 2012;234(1):157-163.

42. Malafaya PB, Elvira C, Gallardo A, San Román J, Reis RL. Porous starch-based drug delivery systems processed by a microwave route. J Biomater Sci Polym Ed. 2001;12(11):1227-1241.

43. Zhang $Z$, Huang J, Jiang $S$, et al. Porous starch based self-assembled nano-delivery system improves the oral absorption of lipophilic drug. Int J Pharm. 2013;444(1-2):162-168.

44. García-González CA, Jin M, Gerth J, Alvarez-Lorenzo C, Smirnova I. Polysaccharide-based aerogel microspheres for oral drug delivery. Carbohydr Polym. 2015;117:797-806.

45. Sujka M, Jamroz J. a-Amylolysis of native potato and corn starches - SEM, AFM, nitrogen and iodine sorption investigations. LWT-Food Sci Technol. 2009;42(7):1219-1224.

46. Sujka M, Jamroz J, Kwiatkowski R. Influence of a-amylolysis on the formation of electron density inhomogeneities on the surface of starch granules. Starch/Stärke 2011;63(1):17-23.

47. Meer TA, Moravkar K, Pawar J, Amin P. Cross-linked porous starch particles - a promising carrier. Polim Med. 2015;45(1):11-19.

48. Lacerda LD, Leite DC, Soares RMD, da Silveira NP. Effects of a-amylase, amyloglucosidase, and their mixture on hierarchical porosity of rice starch. Starch/Stärke. 2018;70(11-12):1-7. 
